\title{
HALAL FOOD PADA HIDANGAN NASI GORENG DI KECAMATAN SUKASARI BANDUNG
}

\author{
Ajeng Fatimah Noor Islami ${ }^{1}$, Sudewi Yogha ${ }^{1}$, Karpin $^{1}$ \\ Program Studi Pendidikan Tata Boga, Departemen Pendidikan Kesejahteraan \\ Keluarga, Fakultas Teknologi dan Kejuruan, Universitas Pendidikan Indonesia
}

Afanisshop@gmail.com

\begin{abstract}
Abstrak: Halal food merupakan hidangan maupun minuman yang boleh dikonsumsi menurut syariat Islam. Pada proses pengolahan, pemilihan bahan, tempat penyimpanan, sumber bahan baku yang digunakan harus berasal dari yang dibolehkan syariat Islam serta terhindar dari najis. Nasi goreng merupakan hidangan yang sangat digemari oleh masyarakat, namun banyak penjual yang masih menggunakan bahan dan bumbu yang tidak halal. Tingkat pengetahuan mengenai halal food merupakan faktor yang menentukan penjual menggunakan bahan-bahan tidak halal. Penelitian ini dilatarbelakangi karena sesuai dengan undang-undang no. 33 tahun 2014 mengenai jaminan produk halal dan pada tahun 2019 semua produk pangan wajib bersertifikat halal. Tujuan dari penelitian ini yaitu untuk memperoleh data mengenai sejauh mana pemahaman para penjual nasi goreng mengenai halal food, serta pemaham para penjual nasi goreng mengenai pemilihan bahan dan bumbu halal. Metode yang digunakan pada penelitian ini yaitu kuantitatif dengan melakukan survey dan instrument berupa test. Hasil penelitian ini menunjukkan para penjual nasi goreng yang berada di kecamatan Sukasari menguasai pengetahuan halal food. Sedangkan untuk pengetahuan dalam memilih bahan dan bumbu yang digunakan pada hidangan nasi goreng, penjual nasi goreng menguasai pengetahuan bahan dan bumbu halal. Namun kurangnya kesadaran mengenai halal food membuat para penjual tetap menggunakan bumbu-bumbu yang non halal. Berdasarkan hasil penelitian ini diharapkan para penjual dapat lebih meningkatkan pengetahuan dan kesadaran mengenai halal food agar makanan yang disajikan terjamin status kehalalannya, serta untuk para konsumen lebih berhati-hati dalam memilih hidangan yang akan dikonsumsi, dan untuk lembaga terkait diharapkan mampu meningkatkan sosialiasasi kepada masyarakat mengenai pangan halal.
\end{abstract}

Kata kunci : Pengetahuan, Halal Food, Nasi Goreng

\section{PENDAHULUAN}

Kecamatan Sukasari merupakan salah satu kecamatan yang berada di Kota Bandung terdiri dari empat kelurahan dengan luas lahan sebesar 627,518 Ha. Mayoritas penduduk di Kecamatan Sukasari menganut agama Islam. Terlihat dari data Dinas Kependudukan dan Catatan Sipil tahun 2017. Sebanyak 67.508 jiwa masyarakat di Kecamatan Sukasari menganut agama Islam.

Sebagai salah satu kota destinasi wisata dengan mayoritas penduduk beragama Islam tentunya para penjual di bidang kuliner harus mampu membuat hidangan dengan konsep halal food. Halal food merupakan makanan dan minuman yang dibolehkan secara syariat Islam bukan hanya bahan-bahan yang digunakan, melainkan teknik pengolahan, cara mendapatkan bahan yang aman untuk di konsumsi bagi kesehatan tubuh. Untuk itulah penjual makanan harus menjamin kehalalan thayyiban dari suatu produk yang di jual.

Makanan yang dihasilkanpun harus terbuat dari bahan-bahan yang diperbolehkan oleh syariat Islam, sesuai dengan Undang-undang RI No.33 tahun 2014 tentang Jaminan 
Produk Halal (JPH) telah di tetapkan sebagai landasan untuk menjamin kepastian hukum pengaturan kehalalan suatu produk. Penyelenggaraan JPH diharapkan memberikan kenyamanan, keamanan, keselamatan dan kepastian ketersediaan produk halal bagi masyarakat serta meningkatkan nilai tambah bagi pelaku usaha untuk memproduksi dan menjual produk halal. Sehingga pemerintah mewajibkan pada tahun 2019 semua produk obat dan makanan wajib memiliki sertifikasi Halal yang diakui oleh pemerintah.

Halalan Thayibban adalah kata halalan (yang dibolehkan Allah SWT) diberikan kata sifat thayyiban. Artinya makanan yang berguna bagi tubuh, tidak merusak, tidak menjijikan, rasa enak, tidak kadaluarsa dan tidak bertentangan dengan perintah Allah SWT karena tidak diharamkan sehingga kata thayyiban menjadi illah (alasan) dihalalkan sesuatu (Al-Qur'an dan Tafsirnya, jilid 1, hal. 247, Kemenag RI).

Salah satu hidangan yang banyak di jumpai di Kota Bandung yaitu Nasi Goreng. Nasi goreng merupakan hidangan popular di Indonesia yang sangat di gemari oleh berbagai kalangan masyarakat seperti orang dewasa, remaja, bahkan kanakkanak. Hal ini terbukti dengan terpilihnya hidangan nasi goreng sebagai hidangan terlezat nomor dua di dunia melalu voting yang di lakukan oleh Cable News Network (CNN) pada tahun 2017. Hidangan nasi goreng memiliki beberapa komponen diantaranya nasi, bumbu, minyak, dan bahan pelengkap yang terdiri dari kecap, saus dan bahan isian. (edition.cnn.com/travel).

Hidangan nasi goreng merupakan pengaruh negara Tionghoa yang oleh masyarakat Tionghoa di bawa masuk ke Negara Indonesia. Oleh sebab itu bumbu-bumbu khas Tionghoa juga ikut digunakan pada hidangan nasi goreng di Indonesia.

Berdasarkan hasil studi pendahulu melalui observasi yang peneliti lakukan ke berbagai penjual nasi goreng di wilayah Kecamatan Sukasari teramati dalam bumbu yang digunakan penjual nasi goreng menggunakan angciu. Terdapat beberapa alasan yang melatarbelakangi penjual menggunakan angciu sebagai bumbu. Para penjual beranggapan bahwa angciu akan menguap dalam proses pemasakan, sehingga zat dimaksud tidak akan terdapat dalam hasil masakan sehingga hukum makanan tersebut menjadi halal. Para penjual pula tidak memahami bahwa angciu merupakan bahan yang bersifat khamar sehingga menganggap angciu hampir sama dengan kecap.

Menurut Majelis Ulama Indonesia angciu, yang biasa digunakan sebagai penyedap rasa atau pengempuk daging yang dimasak. Angciu juga memiliki istilah lain yaitu arak masak, arak merah, sari tape. Angciu berasal dari alkohol dan statusnya haram. Selain mengandung alcohol angciu juga bersifat khamr yaitu memabukan serta membahayakan kesehatan tubuh. (halalmui.org)

\section{Rumusan Masalah Penelitian}

Bagaimana halal food pada hidangan nasi goreng di kecamatan Sukasari?

\section{Tujuan Penelitian}

Tujuan pada penelitian ini yaitu agar memperoleh informasi mengenai sejauh mana pengetahuan penjual nasi goreng mengenai halal food.

\section{Manfaat Penelitian}

Dari segi teoritis penelitian ini di harapkan mampu menunjukkan tingkat 
pemahaman mengenai halal food di kalangan penjual hidangan nasi goreng di Kecamatan Sukasari. Dan memberikan informasi mengenai kriteria halal food sesuai syariat Islam.

\section{METODE}

Metode Penelitian yang digunakan pada penelitian ini yaitu metode survey dengan pendekatan kuantitatif. Teknik yang digunakan pada penelitian ini yaitu survey dengan menggunakan tes sebagai bentuk instrument. Survey dilakukan pada saat penjual nasi goreng bekerja. Para penjual diberikan instrument yang berisi soal tes untuk kemudian di isi oleh para penjual dengan memilih jawaban yang paling di anggap benar oleh para penjual.

Pada penelitian ini populasi yang digunakan yaitu para penjual nasi goreng yang berada kecamatan Sukasari yang memiliki empat kelurahan yaitu kelurahan Isola, Kelurahan Sukarasa, Kelurahan Sarijadi, dan Kelurahan Geger Kalong.

Berdasarkan hasil pengamatan peneliti di lingkungan kecamatan Sukasari jumlah penjual nasi goreng sebanyak 60 penjual. Pada kelurahan Geger Kalong terdapat 21 penjual nasi goreng, kelurahan Isola terdapat 14 penjual nasi goreng, kelurahan Sarijadi terdapat 16 penjual nasi goreng dan pada kelurahan Sukarasa terdapat 9 penjual nasi goreng.

Pada penelitian ini yang dilakukan oleh peneliti yaitu sensus. Sensus dilakukan dikarenakan peneliti tidak melakukan teknik sampling, hal ini karena seluruh anggota populasi yaitu penjual nasi goreng yang berada pada wilayah kecamatan Sukasari dijadikan responden dalam penelitian ini.

Teknik pengumpulan data yang di gunakan yaitu test. Test pada penelitian ini digunakan untuk mengukur pengetahuan para penjual nasi goreng yang berada di kecamatan Sukasari mengenai halal food. Test dibuat berdasarkan kisi-kisi instrument yang telah disusun sebelumnya.

Pada instrument penelitian ini digunakan dua jenis test. Test pada tahap pertama yaitu menggunakan jenis soal pilihan ganda (multiple choice) dengan empat pilihan jawaban, dan test kedua yaitu menggunakan pertanyaan yang menggunakan dua pilihan jawaban pasti yang tersedia yaitu halal dan tidak halal.

Pertanyaan yang akan disajikan kepada responden harus melalui tahap validitas. Pada penelitian ini validitas dilakukan dengan cara Expert Judgement. Expert Judgement merupakan proses validitas dimana para ahli memberikan pendapatnya tentang aspek yang telah disusun. Para ahli kemudian memberikan pertimbangan mengenai tes yang akan digunakan, untuk dilakukan perbaikan atau pertanyaan dianggap baik untuk digunakan dalam mengukur pengetahunan halal food pada penelitian ini.

Teknik analisa data dalam penelitian ini menggunakan analisis deskriptif serta skala pengukuran yang digunakan yaitu menggunakan Skala Guttman. Penggunaan Skala Guttman selain dapat berupa pilihan ganda juga dapat disusun berupa checklist. Pada instrument ini setiap jawaban benar akan diberikan skor 1 dan setiap jawaban salah akan diberikan skor 0 .

Data yang telah diperoleh akan diolah dengan presentase data yang digunakan untuk membuat frekuensi jawaban sehingga hasil test akan terlihat dalam bentuk persentase pada penelitian ini rumus persentase yang digunakan merujuk pada Sudjana (2004, hlm. 129): 


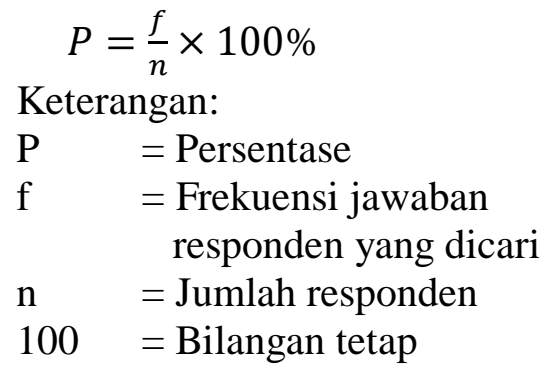

Setelah hasil persentase didapatkan, kemudian dapat tersebut di analisis untuk kemudian ditafsirkan. Penafsiran data dilakukan dengan menggunakan kriteria batasan berdasarkan jumlah responden yang menjawab. Data interval tersebut juga dianalisis dengan menghitung perolehan skor jawaban berdasarkan skoring setiap jawaban dari responden, hal ini sesuai dengan yang dikemukakan oleh sugiyono (2014, hlm.95) berdasarkan skor yang telah ditetapkan maka akan diperoleh skor maksimal yang selanjutnya dapat diperoleh dalam bentuk persentase. Dari skor maksimal dan persentase dapat dilakukan dengan batasanbatasan untuk penafsiran data.

Setelah penafsiran tersebut, untuk mendapatkan data yang jelas terhadap jawaban responden dari pertanyaan yang diajukan kemudian ditafsirkan dengan menggunakan kriteria penafsiran data yang merujuk pada pendapat Riduwan (2010, hlm 184) yaitu:

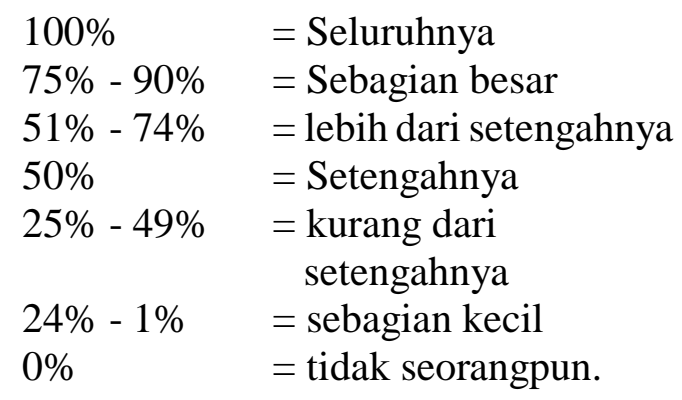

Data dianalasis untuk mengetahui kategori pengetahuan halal food penjual nasi goreng dengan mengkonversikan data kedalam skala 100. Tujuan dilakukan penilaian ini agar mengukur pengetahuan penjual nasi goreng mengenai halal food. Data yang diperoleh kemudian ditafsirkan menggunakan kriteria data yang merujuk pada pendapat Riduwan (2010, hlm. 15):

Tabel 1. Penafsiran Data Persentase Pengetahuan

\begin{tabular}{|c|c|}
\hline Persentase & $\begin{array}{c}\text { Kriteria } \\
\text { Penguasaan }\end{array}$ \\
\hline $81 \%-100 \%$ & Sangat dikuasai \\
\hline $61 \%-80 \%$ & Dikuasai \\
\hline $41 \%-60 \%$ & Cukup dikuasai \\
\hline $21 \%-40 \%$ & Kurang dikuasai \\
\hline $0 \%-20 \%$ & Tidak dikuasai \\
\hline
\end{tabular}

\section{HASIL DAN PEMBAHASAN}

1. Pengetahuan Halal Food Penjual Nasi Goreng di Kecamatan Sukasari.

Pengetahuan halal food penjual nasi goreng merupakan sebuah kemampuan yang dimiliki oleh penjual nasi goreng sebagai pelaku industri di bidang jasa boga yang terdiri pemilihan bahan, penyimpanan bahan, pengolahan bahan, pengemasan, pendistribusian hingga penyajian makanan.

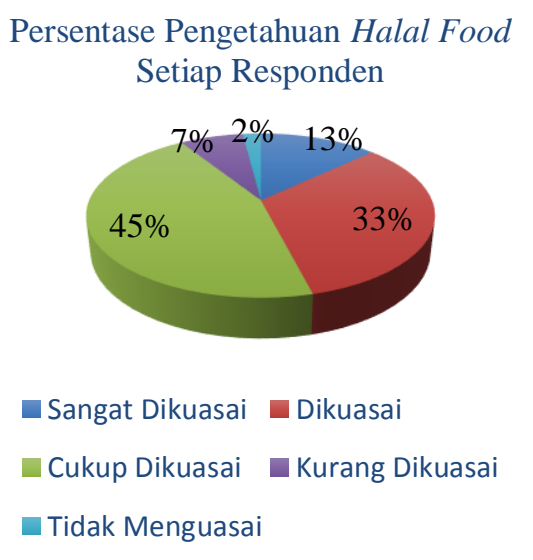

Gambar 1.1 Diagram pie rata-rata pengetahuan halal food 
Hasil penelitian menunjukkan bahwa rata-rata persentase nilai pengetahuan responden berkaitan dengan pengetahuan halal food adalah $65,2 \%$ yang berada pada kategori dikuasai. Namun sebanyak $13 \%$ atau sebesar 8 responden termasuk kedalam kategori sangat menguasai pengetahuan mengenai halal food. Sebanyak $33 \%$ responden atau 20 orang penjual nasi goreng berada pada kategori dikuasai mengenai pengetahuan halal food. Sebanyak $45 \%$ atau 27 responden berada pada kategori cukup menguasai pengetahuan mengenai halal food. Sebanyak $7 \%$ responden atau 4 orang responden berada pada kategori cukup menguasai. Sebanyak 2\% responden atau 1 orang responden berada pada kategori tidak menguasai pengetahuan mengenai halal food. Berdasarkan hasil analisis dapat disimpulkan bahwa pengetahuan halal food pada penjual nasi goreng di kecamatan Sukasari Bandung berada pada kategori dikuasai.

Penelitian ini sesuai dengan penelitian yang dilakukan oleh Nurul Fitria (2017) dengan judul "Persepsi Halal Food di Kota Bandung" berdasarkan hasil penelitian tersebut didapatkan kesimpulan bahwa menunjukkan bahwa persepsi halal food produsen adalah baik, yang artinya para produsen makanan dan minuman food street di kota Bandung sudah memiliki persepsi baik terhadap halal food melalui pengetahuan, keyakinan, prilaku, dan tindakan yang dimiliki para responden produsen. Sedangkan pada persepsi halal food konsumen adalah sangat baik, yang artinya para konsumen makanan dan minuman street food di kota Bandung sudah memiliki persepsi baik terhadap halal food melalui pengetahuan, keyakinan, prilaku, dan tindakan yang dimiliki para responden.

\section{Pemilihan Bahan dan Bumbu Halal.}

Tabel 1.2 Pengetahuan bahan dan bumbu halal dan non halal

\begin{tabular}{|c|l|c|c|c|c|}
\hline No. & \multirow{2}{*}{ Nama Bahan } & \multicolumn{2}{|c|}{ Halal } & \multicolumn{2}{c|}{$\begin{array}{l}\text { Tidak } \\
\text { Halal }\end{array}$} \\
\cline { 3 - 6 } & & f & \% & f & $\%$ \\
\hline 1. & Angciu & 18 & 30 & 42 & 70 \\
\hline 2. & Arak Masak & 10 & 17 & 50 & 83 \\
\hline 3. & Mirin & 23 & 38 & 37 & 62 \\
\hline 4. & $\begin{array}{l}\text { Hewan yang } \\
\text { disembelih } \\
\text { tanpa sesuai } \\
\text { syariat Islam }\end{array}$ & 0 & 0 & 60 & 100 \\
\hline 5. & $\begin{array}{l}\text { Sosis tanpa } \\
\text { label halal resmi } \\
\text { MUI }\end{array}$ & 10 & 17 & 50 & 83 \\
\hline 6. & $\begin{array}{l}\text { Bakso tanpa } \\
\text { label halal resmi } \\
\text { MUI }\end{array}$ & 10 & 17 & 50 & 83 \\
\hline
\end{tabular}

Pada tabel tersebut menunjukkan $30 \%$ (18 responden) atau kurang dari setengahnya responden berpendapat bahwa angciu halal dan berada pada kategori kurang dikuasai, serta sebagian kecil responden yaitu 10 responden $(17 \%)$ berpendapat arak masak termasuk kedalam kategori bumbu halal. Berdasarkan data tersebut maka pengetahuan sebagian kecil responden termasuk kedalam kategori tidak dikuasai. Sedangkan kurang dari setengah responden $38 \% \quad$ (23 responden) berpendapat bahwa mirin merupakan termasuk kategori bumbu halal. Bakso dan sosis merupakan bahan tambahan yang biasa digunakan pada proses pembuatan nasi goreng, berdasarkan data yang terdapat pada tabel, sebagian kecil responden yaitu 10 responden (17\%) berpendapat pada masing-masing bahan yaitu bakso dan sosis tanpa label halal resmi dari 
Majelis Ulama Indonesia adalah bahan makanan halal.

Tabel 1.3 Penggunaan bahan non halal pada hidangan nasi goreng.

\begin{tabular}{|c|l|c|c|c|c|}
\hline No. & Nama Bahan & \multicolumn{2}{|c|}{ Digunakan } & \multicolumn{2}{|c|}{$\begin{array}{c}\text { Tidak } \\
\text { Digunakan }\end{array}$} \\
\cline { 3 - 6 } & & f & $\%$ & f & $\%$ \\
\hline 1. & Angciu & 8 & 13 & 52 & 87 \\
\hline 2. & Arak Masak & 0 & 0 & 60 & 100 \\
\hline 3. & Mirin & 10 & 17 & 50 & 83 \\
\hline 4. & $\begin{array}{l}\text { Hewan yang } \\
\text { disembelih } \\
\text { tanpa sesuai } \\
\text { syariat Islam }\end{array}$ & 0 & 0 & 60 & 100 \\
\hline 5. & $\begin{array}{l}\text { Sosis tanpa } \\
\text { label halal } \\
\text { resmi MUI }\end{array}$ & 26 & 43 & 34 & 57 \\
\hline 6. & $\begin{array}{l}\text { Bakso tanpa } \\
\text { label halal } \\
\text { resmi MUI }\end{array}$ & 26 & 43 & 34 & 57 \\
\hline
\end{tabular}

Berdasarkan tabel tersebut, mengenai penggunaan bahan-bahan non halal yang digunakan pada proses pembuatan nasi goreng menunjukkan $13 \%$ responden menggunakan angciu pada proses pemasakan, $17 \%$ respon menggunakan mirin, serta $43 \%$ penjual nasi goreng menggunakan bakso dan sosis tanpa label Halal untuk proses pembuatan hidangan nasi goreng.

Pengetahuan pemilihan bahan dan bumbu halal para penjual nasi goreng di kecamatan Sukasari menunjukkan lebih dari setengah penjual nasi goreng menguasai pengetahuan dalam memilih bahan dan bumbu halal yang akan digunakan. Namun, kurang dari setengah penjual nasi goreng yang berada di kecamatan Sukasari menunjukkan kurang menguasai pengetahuan dalam memilih bumbu dan bahan halal. Hal ini terlihat dari penjual nasi goreng yang masih beranggapan bumbu-bumbu haram seperti angciu, arak masak, mirin termasuk kedalam kategori bumbu halal. Menurut Majelis Ulama
Indonesia angciu biasa digunakan sebagai penyedap rasa atau pengempuk daging yang dimasak. Angciu juga memiliki istilah lain yaitu arak masak, arak merah, sari tape dan lain-lain. Angciu berasal dari alkohol dan statusnya haram, kandungan alkohol angciu adalah sekitar $15 \%$.

Menurut para ulama di Komisi Fatwa MUI alkohol itu ada yang diharamkan, dan ada pula yang tidak haram. Selanjutnya, khamar yang dibuat dan diproses dari anggur, secara asholah, maupun dari yang selain anggur, seperti tuak, minuman tradisional di Sumatra, atau sake di Jepang, secara eksplisit dan tegas diharamkan dalam Islam. Dalam proses pembuatannya, mulai dari awal pengolahan, fermentasi sampai produk jadi, memang dengan sengaja dimaksudkan untuk menghasilkan minuman yang memabukkan, atau khamar. (www.halalmui.com).

\section{KESIMPULAN}

Berdasarkan penelitian yang dilakukan mengenai Pengetahuan Halal Food Penjual Nasi Goreng di Kecamatan Sukasari menunjukkan bahwa:

1. Para penjual nasi goreng yang berada di kecamatan Sukasari menguasai pengetahuan mengenai halal food.

2. Hampir seluruh penjual nasi goreng di kecamatan Sukasari menguasai pemilihan bahan dan bumbu yang termasuk kedalam kategori halal dan non halal.

\section{REFERENSI}

Apriyantono, A. (2007). Makanan dan Minumam Halal. Bandung : Kiblat Buku Utama

Arikunto, S. (2013). Prosedur Penelitian. Jakarta : Rineke Cipta 
Departemen Pendidikan Nasional. (2017). Pedoman Penulisan Karya Ilmiah. Bandung: UPI
Riduwan. (2010). Dasar-dasar Statistika. Bandung : Alfabeta 